\title{
Trauma Surgery \& Acute Care Open \\ Cost-effectiveness of direct discharge from the emergency department of patients with simple stable injuries in the Netherlands
}

\author{
Thijs H Geerdink 지 , ${ }^{1,2}$ Niek J Geerdink, ${ }^{1}$ Johanna M van Dongen, ${ }^{3}$ Robert Haverlag, ${ }^{1}$ \\ J Carel Goslings, ${ }^{1,2}$ Ruben N van Veen, ${ }^{1}$ Virtual Fracture Care Study Collaborative
}

\begin{abstract}
- Additional supplemental material is published online only. To view, please visit the journal online (http://dx.doi. org/10.1136/tsaco-2021000763).
\end{abstract}

'Department of Trauma Surgery, OLVG, Amsterdam, The Netherlands

${ }^{2}$ Department of Surgery, Amsterdam UMC, location AMC Amsterdam, The Netherlands ${ }^{3}$ Department of Health Sciences, Vrije Universiteit Amsterdam, Amsterdam, The Netherlands

Correspondence to Dr. Thijs H Geerdink; t.h. geerdink@olvg.n

THG and NJG are joint first authors.

Received 24 April 2021 Accepted 1 September 2021

(C) Author(s) (or their employer(s)) 2021. Re-use permitted under CC BY-NC. No commercial re-use. See rights and permissions. Published by BMJ.

To cite: Geerdink $\mathrm{TH}$, Geerdink NJ, van Dongen JM, et al. Trauma Surg Acute Care Open 2021:6:e000763.

\section{ABSTRACT}

Background Approximately one-third of musculoskeletal injuries are simple stable injuries (SSIs). Direct discharge (DD) from the emergency department (ED) of patients with SSIs reduces healthcare utilization, without compromising patient outcome and experience, when compared with "traditional" care with routine follow-up. This study aimed to determine the costeffectiveness of DD compared with traditional care from a societal perspective.

Methods Societal costs, including healthcare, work absenteeism, and travel costs, were calculated for patients with an SSI, 6 months before (pre-DD cohort) and after implementation of DD (DD cohort). The pre-DD cohort was treated according to local protocols. The DD cohort was treated using orthoses, discharge leaflet, smartphone application, and telephone helpline, without scheduling routine follow-up. Effect measures included generic health-related quality of life (HR-QoL; EuroQol Five-Dimensional Questionnaire); disease-specific HR-QoL (functional outcome, different validated questionnaires, converted to 0-100 scale); treatment satisfaction (Visual Analog Scale (VAS), 1-10); and pain (VAS, 1-10). All data were assessed using a 3-month postinjury survey and electronic patient records. Incremental costeffectiveness ratios were calculated and uncertainty was assessed using bootstrapping techniques.

Results Before DD, 144 of 348 participants completed the survey versus 153 of 371 patients thereafter. There were no statistically significant differences between the pre-DD cohort and the DD cohort for generic HR-QoL $(0.03 ; 95 \% \mathrm{Cl}-0.01$ to 0.08$)$, disease-specific HR-QoL $(4.4 ; 95 \% \mathrm{Cl}-1.1$ to 9.9$)$, pain $(0.08 ; 95 \% \mathrm{Cl}-0.37$ to 0.52$)$ and treatment satisfaction $(-0.16 ; 95 \% \mathrm{Cl}$ -0.53 to 0.21 ). Total societal costs were lowest in the DD cohort (-€822; 95\% Cl -€1719 to -€67), including healthcare costs (-€168;95\% Cl-€205 to -€131) and absenteeism costs (-€645; 95\% Cl -€1535 to €100). The probability of DD being cost-effective was 0.98 at a willingness-to-pay of $€ 0$ for all effect measures, remaining high with increasing willingness-to-pay for generic HR-QoL, disease-specific HR-QoL, and pain, and decreasing with increasing willingness-to-pay for treatment satisfaction.

Discussion DD from the ED of patients with SSI seems cost-effective from a societal perspective. Future studies should test generalizability in other healthcare systems and strengthen findings in larger injuryspecific cohorts.

Level of evidence $\|$.

\section{INTRODUCTION}

In the Netherlands, 659000 of 2 million annual emergency department (ED) visits concern musculoskeletal injuries, such as fractures (43\%), soft tissue injuries (15\%), distortions (5\%), dislocations (4\%), and tendon injuries (3\%). ${ }^{1}$ Their economic impact is substantial. That is, in the Netherlands, total annual direct healthcare costs and lost productivity costs after injuries are estimated at $€ 2.4$ billion and $€ 1.4$ billion, respectively. ${ }^{1}$ Epidemiological studies show that the incidence of injuries is increasing. ${ }^{2}$ To illustrate, for example, for extremity fractures in the Netherlands, in 2004 the total number was 129188 versus 170673 in 2010 and 260800 in $2019 . .^{12}$ A change in healthcare capacity and resources is warranted in anticipation of a further increasing demand and to maintain high-quality trauma care. ${ }^{2}$

Traditionally, majority of patients with musculoskeletal injuries are reviewed in a fracture clinic within 1 week after initial ED assessment and at regular fixed periods in the weeks thereafter. Consequently, these clinics are characterized by the routine attendance of large numbers of unselected patients who often have relatively minor injuries with excellent prognosis and do not require intervention. ${ }^{34}$

Recent studies indicate that a large proportion of musculoskeletal injuries are simple stable injuries (SSIs) that require reassurance and information, but not routine review. ${ }^{34}$ There is growing evidence that suggests that direct discharge (DD) from the ED of patients with these SSIs is a safe and effective alternative to "traditional" care with routine follow-up, which reduces healthcare utilization (ie, hospital visits and imaging), without compromising patient outcome (eg, functional outcome) and experience (eg, satisfaction with treatment). ${ }^{5-24}$

Although a relatively small number of previous studies included cost estimations before and after $\mathrm{DD},{ }^{7-11}$ to our knowledge currently no studies have been performed regarding the cost-effectiveness. Therefore, the aim of this study was to determine whether DD from the ED of patients with SSIs is cost-effective from a societal perspective compared with "traditional" care with routine follow-up.

\section{METHODS}

Design

This cost-effectiveness analysis (CEA) was based on data from a prospective non-inferiority trial for 11 
SSIs performed in the OLVG Hospital, a level 2 trauma center and teaching hospital in Amsterdam, the Netherlands. ${ }^{25}$

\section{Participants}

All consecutive ED patients with an isolated SSI were asked to participate during a 1-year period (November 15, 2018November 15,2019$).{ }^{25}$ DD was implemented at the midpoint (May 20, 2019), dividing participants into the pre-DD cohort and the DD cohort. Exclusion criteria were inability to understand/complete Dutch survey; initial treatment in the ED of a different hospital; other reasons for follow-up (eg, social care reasons); eye/motor/verbal score $<15$ at presentation and highenergy trauma; treatment continued elsewhere (eg, closer to home); and alcohol/drug intoxication..$^{25}$

All patients who were willing to participate provided written informed consent in the ED and received a 3-month postinjury survey containing questions regarding employment status, education level, health-related quality of life (HR-QoL), functional outcome, satisfaction, pain, primary healthcare use, and work absenteeism. Furthermore, the electronic patient record of all participants was evaluated after 1 year to assess secondary healthcare use, including hospital visits, imaging (eg, X-ray, CT scan, MRI scan) and adverse outcomes.

\section{Treatment}

Traditional care

Before DD, all patients with SSI were treated using local protocols. This usually involved application of a cast/splint/bandage and review in the fracture clinic 1 week after injury. Frequently, one or multiple subsequent visits followed in the weeks thereafter for assessment of functional outcome and/or removal of cast material.

\section{Direct discharge}

The implementation of DD standardized the immobilization of SSIs to bandage or removable orthoses (table 1). Follow-up appointments are no longer scheduled routinely. Instead, ED physicians provide information about the SSI and the expected recovery, which is also summarized in discharge leaflets. These leaflets are available on paper as well as digitally by means of a smartphone application for iOS and Android, which also contains videos of physical exercises to improve recovery and videos explaining how to reapply immobilization after removal (eg, after taking a shower). Patients are instructed to contact our telephone helpline in case of questions or concerns. The X-rays of all ED patients, including patients with SSIs, are reviewed daily by an orthopedic trauma surgeon and a radiologist. If based on this review an injury is not deemed suitable for DD (eg, the injury is not an SSI), a face-to-face appointment is scheduled.

\section{Effect measures}

Cost-effectiveness was assessed for four outcomes: (1) generic HR-QoL, (2) disease-specific HR-QoL, (3) satisfaction with treatment, and (4) pain. Questionnaires used to assess generic and disease-specific HR-QoL were only available for patients $\geq 4$ years old. Therefore, these outcomes were not assessed for participants $<4$ years old.

Generic HQ-QoL was assessed using the EuroQol FiveDimensional Questionnaire (EQ-5D). The five-level version (EQ-5D-5L) was completed by all participants $\geq 18$ years old and also by children $\geq 12$ years old if self-completing the questionnaire. ${ }^{26}$ The youth version (EQ-5D-Y) was used for all other children 4 to 17 years old. ${ }^{27}$ Proxy versions were used if a parent/
Table 1 Simple and stable injuries, criteria, and immobilization

\begin{tabular}{|c|c|c|c|}
\hline Injury & Pediatric/adult & Criteria & $\begin{array}{l}\text { Immobilization } \\
\text { after DD }\end{array}$ \\
\hline $\begin{array}{l}\text { Pediatric clavicle } \\
\text { Fx }\end{array}$ & Pediatric & $\begin{array}{l}\text { Age } \leq 14 \text {. } \\
\text { No indication for } \\
\text { surgical treatment. }\end{array}$ & Sling \\
\hline $\begin{array}{l}\text { Radial head/ } \\
\text { neck Fx }\end{array}$ & Adult & $\begin{array}{l}\text { Head: Mason type 1, } \\
\text { neck: undisplaced. } \\
\text { Positive fatpad sign. }\end{array}$ & $\begin{array}{l}\text { Pressure bandage, } \\
\text { sling }\end{array}$ \\
\hline $\begin{array}{l}\text { Greenstick or } \\
\text { torus/buckle- } \\
\text { type Fx of the } \\
\text { distal radius }\end{array}$ & Pediatric & $\begin{array}{l}\text { Acceptable } \\
\text { angulation-based } \\
\text { residual growth. } \\
\text { Torus/buckle type: } \\
\text { isolated ulna Fx, } \\
\text { isolated radius Fx or } \\
\text { both. } \\
\text { Greenstick type: } \\
\text { isolated ulna Fx or } \\
\text { isolated radius Fx. }\end{array}$ & $\begin{array}{l}\text { Removable wrist } \\
\text { brace }\end{array}$ \\
\hline $\begin{array}{l}\text { Fifth metacarpal } \\
\text { neck Fx }\end{array}$ & Adult & $\begin{array}{l}\text { Volar } \\
\text { angulation }<70^{\circ} . \\
\text { No rotational } \\
\text { deviation. }\end{array}$ & $\begin{array}{l}\text { Buddy strap and } \\
\text { pressure bandage }\end{array}$ \\
\hline Mallet finger & Adult & $\begin{array}{l}\text { Either bony or } \\
\text { tendinous. } \\
\text { Treated } \\
\text { conservatively. }\end{array}$ & Mallet splint \\
\hline $\begin{array}{l}\text { Weber A-type } \\
\text { ankle Fx }\end{array}$ & Adult & $\begin{array}{l}\text { Dislocation }<2 \mathrm{~mm} \text {. } \\
\text { No signs of stage } 2 \\
\text { supination-adduction- } \\
\text { type injury. }\end{array}$ & $\begin{array}{l}\text { Tubigrip and ankle } \\
\text { brace }\end{array}$ \\
\hline $\begin{array}{l}\text { Avulsion-type } \\
\text { ankle Fx }\end{array}$ & Adult & $\begin{array}{l}\text { Either lateral or } \\
\text { medial malleolus or } \\
\text { tarsal bones. }\end{array}$ & $\begin{array}{l}\text { Tubigrip and ankle } \\
\text { brace }\end{array}$ \\
\hline $\begin{array}{l}\text { Fx of fifth } \\
\text { metatarsal base }\end{array}$ & Adult & $\begin{array}{l}\text { Fx located in either } \\
\text { zone } 1 \text { or zone } 2 \text {. } \\
\text { Dislocation } \leq 4 \mathrm{~mm} \text {. }\end{array}$ & Walker boot \\
\hline Fx of greater toe & Both & $\begin{array}{l}\text { - Either proximal or } \\
\text { distal phalanx Fx. } \\
\text { - Undisplaced. }\end{array}$ & $\begin{array}{l}\text { Spica pressure } \\
\text { bandage and } \\
\text { bandage shoe }\end{array}$ \\
\hline Fx of lesser toe & Both & $\begin{array}{l}\text { Any isolated Fx. } \\
\text { No indication for } \\
\text { surgical treatment. }\end{array}$ & Buddy strap \\
\hline $\begin{array}{l}\text { Bicycle spoke } \\
\text { injury }\end{array}$ & Pediatric & $\begin{array}{l}\text { No Fx based on } \\
\text { radiograph. } \\
\text { Superficial wound. }\end{array}$ & Pressure bandage \\
\hline
\end{tabular}

DD, direct discharge; Fx, fracture.

caregiver completed the survey. The participants' EQ-5D-5L or EQ-5D-Y health states were converted to utility values using the Dutch EQ-5D-5L and EQ-5D-3L value sets, respectively. ${ }^{28} 29$ Utility values indicate the preference or desirability of a certain health state on a scale anchored at 0 (equal to death) to 1 (equal to optimal health).

Disease-specific HR-QoL was assessed in participants $\geq 4$ years old using four different validated functional outcome questionnaires based on age and type of injury (online supplemental appendix A): (1) shortened version of the Disabilities of the Arm, Shoulder and Hand (QuickDASH),,$^{30}$ (2) Lower Extremity Functional Scale, ${ }^{31}$ (3) Short Form of the Patient-Reported Outcomes Measurement Information System (PROMIS) Upper Extremity, and (4) Short Form of the PROMIS Mobility. ${ }^{32}{ }^{33}$ To compare disease-specific HR-QoL for all participants, the individual functional outcome scores were converted to a single scale ranging 
from 0 (worst functional outcome) to 100 (best functional outcome). ${ }^{34}$

Satisfaction with treatment was assessed using a Visual Analog Scale (VAS), ranging from $0 \mathrm{~mm}$ (very dissatisfied) to $100 \mathrm{~mm}$ (very satisfied). ${ }^{25}$ Pain was assessed on a VAS from $0 \mathrm{~mm}$ (no pain) to $100 \mathrm{~mm}$ (extremely painful). Both scores were converted from a 0 to 100 scale to a 0 to 10 scale.

\section{Cost measures}

Costs were assessed from a societal perspective, including healthcare costs, work absenteeism costs, and travel costs.

Healthcare costs included primary healthcare costs (eg, visits to the general practitioner (GP) or physiotherapist for follow-up of SSI) and secondary healthcare costs (eg, ED visits, immobilization materials used, follow-up appointments, no-shows, and imaging)..$^{35}$ Healthcare costs were valued using Dutch standard costs, and if unavailable, prices from professional organizations and hospital accounting records (online supplemental appendix B).

Work absenteeism costs were based on patient absenteeism and parent absenteeism. Patient absenteeism was estimated using the number of days patients had to take leave from work after sustaining their injury, as well as the number of hours patients had to take leave from work to attend their fracture clinic appointment(s). Parent absenteeism costs were estimated using the number of hours parents had to take time off from work to accompany their child during a hospital visit. For patient absenteeism, costs were calculated using the friction cost approach (FCA) and gender-specific price weights. The FCA assumes that costs are limited to the friction period, that is, the period needed to replace a sick worker, which is 12 weeks in the Netherlands. If applicable, absenteeism costs were therefore truncated at 12 weeks. In case of parent absenteeism, the accompanying parent's gender was unknown, and consequently gender-specific price weights could not be used. Therefore, these costs were calculated using the average productivity costs rate of all Dutch adults. ${ }^{35}$

Travel costs per hospital visit were assessed using previously collected hospital survey data on the type of transport and the average distance from a patient's home to the nearest hospital in the Netherlands and valued using Dutch standard prices (online supplemental appendix B). ${ }^{35}$

All costs were converted to Euros 2019 using Dutch consumer price indices. Discounting of costs was not necessary because follow-up was not more than 12 months. ${ }^{35-39}$

The following baseline characteristics were assessed: age, gender, education level (low/middle/high), ${ }^{40}$ school/work status, and type of injury.

\section{Statistical analysis}

Statistical analysis was performed using SPSS V.27.0 (IBM, NY, USA) and STATA V.16 (StataCorp, TX, USA). ${ }^{4142}$ As children $<4$ years old did not receive EQ-5D and functional outcome questionnaires, analyses were performed for two groups separately. That is, the CEAs for satisfaction with treatment and pain were based on data of all participants, whereas the CEAs for generic HR-QoL and disease-specific HR-QoL were based on data of participants $\geq 4$ years old only.

Aggregate and disaggregate cost differences were estimated using linear regression analyses adjusted for patients' propensity score and work status (yes/no). A propensity score indicates the probability of a patient being assigned to an intervention group given a set of baseline characteristics. ${ }^{43}$ In our study, the propensity score was estimated using cohort (pre-DD cohort/DD cohort), age, gender, and injury type, using the pscore package in STATA.

Seemingly unrelated regression (SUR) analyses were performed to estimate the differences in costs $(\Delta \mathrm{C})$ and effects $(\Delta \mathrm{E})$. Cost differences were adjusted for propensity score and work status, whereas effect differences were adjusted for propensity score. Incremental cost-effectiveness ratios (ICERs) were calculated by dividing the differences in total societal costs by the differences in effects (ie, $\Delta \mathrm{C} / \Delta \mathrm{E}$ ). The $95 \%$ CIs around all cost differences were estimated using bias-corrected and accelerated (BCA) bootstrapping, with 5000 replications. BCA bootstrapping was also used to graphically illustrate the uncertainty surrounding the ICER by plotting bootstrapped incremental cost-effect pairs (CE pairs) on cost-effectiveness planes (CE planes). ${ }^{44} 45$ A summary measure of the joint uncertainty of costs and effects was presented using cost-effectiveness acceptability curves (CEACs), providing an indication of the probability of DD being costeffective in comparison with traditional care at different values of willingness-to-pay (WTP). WTP is defined as the maximum amount of money decision makers are willing to pay per one extra unit of effect. ${ }^{46}$ For the differences in costs and effects, a $\mathrm{p}$ value of $<0.05$ was considered statistically significant.

\section{Sensitivity analyses}

Three sensitivity analyses were performed to test the robustness of the results of our main analyses: (1) applying the healthcare perspective (SA1), (2) absenteeism costs valued using both agespecific and gender-specific price weights (SA2), and (3) using an alternative propensity score, which was estimated using cohort, age, gender, injury type, and education level (SA3). Both SA2 and SA3 were adjusted for the same covariates as the main analysis, that is, propensity score and work status, whereas SA1 was adjusted for propensity score only.

\section{Patient and public involvement}

Patients were not involved in the design, intervention, research question, or outcome measures of the current study.

\section{RESULTS}

Before DD, 348 of 676 ED patients with SSIs were willing to participate (pre-DD cohort) versus 371 of 784 patients thereafter (DD cohort). Of these, 144 and 153 participants completed the 3-month postinjury survey in the pre-DD cohort and the DD cohort, respectively (figure 1, table 2). The median age in the pre-DD cohort was 26 versus 36 in the DD cohort. There were more employed participants in the DD cohort (47.7\%) compared with the pre-DD cohort (40.3\%). There were no missing data.

\section{Effect measures}

There were no statistically significant effect differences between the pre-DD cohort and the DD cohort for generic HR-QoL, disease-specific HR-QoL, satisfaction with treatment, and pain (table 3).

\section{Cost measures}

On average, total societal costs were $€ 2181$ in the pre-DD cohort versus $€ 1672$ in the DD cohort. After adjusting for propensity score and work status, costs were $€ 822$ lower in the DD cohort compared with the pre-DD cohort $(95 \% \mathrm{CI}$ $-€ 1719$ to $€ 67$; table 4$)$. As for the disaggregate cost differences, there were statistically significant reductions in total healthcare costs $(-€ 168)$, secondary healthcare costs $(-€ 152)$, parent absenteeism $(-€ 47)$, and travel costs $(-€ 7)$ in the DD 


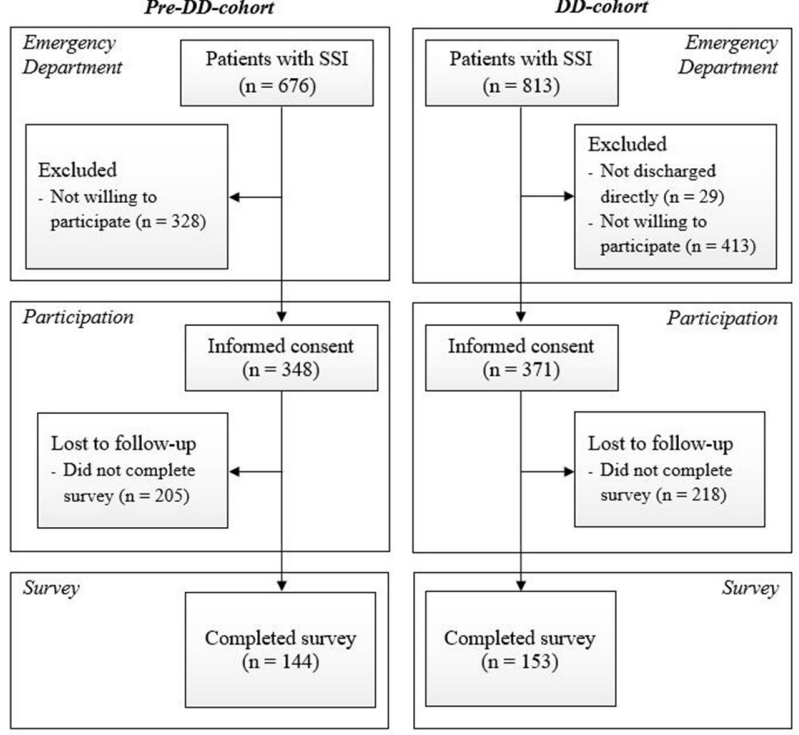

Figure 1 Flow chart depicting the inclusion of patients. In the DD cohort, patients in the emergency department with SSI were used to assess implementation. Patients who provided informed consent were used to assess healthcare utilization, and patients who completed the survey were used to assess patient-reported outcomes and experiences. $\mathrm{DD}$, direct discharge; SSI, simple stable injury.

cohort compared with the pre-DD cohort, whereas there were non-significant reductions in primary healthcare costs $(-€ 16)$, total absenteeism costs $(-€ 645)$, and patient absenteeism costs $(-€ 598)$.

\section{Cost-effectiveness}

The main analyses for generic HR-QoL indicated that total societal costs were lower in the DD cohort compared with the pre-DD cohort (mean $-€ 845 ; 95 \% \mathrm{CI}-€ 1781$ to $-€ 88$ ). The ICER was -26022 , indicating that, on average, a one-point improvement in utility in the DD cohort was associated with a societal cost saving of $€ 26022$ compared with the pre-DD cohort. Majority of the the CE pairs were located in the southeast quadrant (87\%), indicating that, on average, DD was less costly while being more effective than traditional care (table 3, figure $2-1 a) .{ }^{47}$ The CEAC in figure $2-1 b$ indicates that the probability of DD being cost-effective compared with traditional care is 0.98 at a WTP of $0 € /$ one-point improvement, increasing to a maximum of 0.99 for higher values of WTP.

For disease-specific HR-QoL, the ICER was -193 , and $88 \%$ of CE pairs were located in the southeast quadrant, indicating that DD dominated traditional care (ie, less costly and more effective than traditional care (table 3, figure 2-2a). The probability of DD being cost-effective was 0.98 at a WTP of $0 € /$ one-point improvement on the 1 to 100 functional outcome scale, slightly decreasing to 0.95 at a WTP of $€ 3000$ per point improvement (figure 2-2b).

The ICER for satisfaction with treatment was 5213, suggesting that, on average, a one-point decrease on the 1 to 10 VAS was associated with a societal cost saving of $€ 5213$ (table 3). Majority of the CE pairs (74\%) were located in the southwest quadrant, indicating that, on average, DD was less costly and less effective than traditional care (figure 2-3a). The CEAC indicates that the probability of DD being cost-effective compared with traditional care was 0.98 at a WTP of $0 € /$ one-point improvement,
Table 2 Baseline characteristics

\begin{tabular}{|c|c|c|c|}
\hline Characteristics & $\begin{array}{l}\text { Pre-DD cohort } \\
(n=144)\end{array}$ & $\begin{array}{l}\text { DD cohort } \\
(n=153)\end{array}$ & Significance \\
\hline Age, median (IQR) & $26(11-55)$ & $36(13-54)$ & $0.370^{*}$ \\
\hline \multicolumn{4}{|l|}{ Gender, n (\%) } \\
\hline Male & $76(52.8)$ & $68(44.4)$ & $0.151 \dagger$ \\
\hline Type of injury, $n$ (\%) & & & $0.557 \dagger$ \\
\hline Pediatric clavicle Fx & $8(5.6)$ & $8(5.2)$ & \\
\hline Radial head/neck Fx & $24(16.7)$ & $28(18.3)$ & \\
\hline \multicolumn{4}{|l|}{ Pediatric Fx distal radius } \\
\hline Greenstick type & $15(10.4)$ & $9(5.9)$ & \\
\hline Torus type & $21(14.6)$ & $18(11.8)$ & \\
\hline Fifth metacarpal neck Fx & $6(4.2)$ & $1(0.7)$ & \\
\hline Mallet finger & $6(4.2)$ & $4(2.6)$ & \\
\hline Weber A-type ankle Fx & $11(7.6)$ & $14(9.2)$ & \\
\hline Avulsion-type ankle $\mathrm{Fx}$ & $8(5.6)$ & $12(7.8)$ & \\
\hline Fx of fifth metatarsal base & $17(11.8)$ & $20(13.1)$ & \\
\hline Fx of greater toe & $10(6.9)$ & $11(7.2)$ & \\
\hline Fx of lesser toe & $10(6.9)$ & $18(11.8)$ & \\
\hline Bicycle spoke injury & $8(5.6)$ & $10(6.5)$ & \\
\hline Education level, n (\%)‡ & & & $0.568 \dagger$ \\
\hline Low & $70(48.6)$ & $60(39.2)$ & \\
\hline Middle & $23(16.0)$ & 30 (19.6) & \\
\hline High & $51(35.4)$ & $63(41.2)$ & \\
\hline Work/school status, n (\%) & & & $0.061 \dagger$ \\
\hline Going to work & $58(40.3)$ & $73(47.7)$ & \\
\hline Going to school & $59(41.0)$ & $44(28.8)$ & \\
\hline No work/school & $27(18.8)$ & $36(23.5)$ & \\
\hline \multicolumn{4}{|c|}{$\begin{array}{l}\text { *Mann-Whitney U test. } \\
\dagger \chi^{2} \text { test. } \\
\ddagger \text { According to education level by the Dutch Central Agency for Statistics. }{ }^{40} \\
\text { DD, direct discharge; } F x \text {, fracture. }\end{array}$} \\
\hline
\end{tabular}

decreasing with increasing values of WTP $(0.92$ at $€ 1000,0.69$ at $€ 3000$, and a minimum of 0.23 at $€ 30000$; figure 2-3b).

The ICER for pain was -10517 , and $61 \%$ of CE pairs were located in the southeast quadrant, suggesting that, on average, DD dominated traditional care (table 3, figure 2-4a). At a WTP of $0 € /$ one-point improvement on the 1 to $10 \mathrm{VAS}$, the probability of DD being cost-effective compared with traditional care was 0.98 (figure 2-4b). This probability slightly decreased with increasing values of WTP to 0.91 at a WTP of $€ 3000$.

\section{Sensitivity analyses}

In accordance with the main analysis, total costs were statistically significantly lower in the DD cohort compared with the pre-DD cohort when applying the healthcare perspective (SA1), but the magnitude of this effect was smaller. When absenteeism costs were valued using age-specific and gender-specific price weights (SA2), and when an alternative propensity score was used (SA3), results regarding costs, effects, ICERs, and CEACs were comparable with those in the main analysis, although differences in costs were no longer statistically significant.

\section{DISCUSSION}

The results of this study suggest that DD from the ED of patients with SSIs is likely to be cost-effective compared with "traditional" care with routine follow-up, both from a societal 
Table 3 Differences in costs and effects, incremental cost-effectiveness ratios, and cost-effectiveness planes

\begin{tabular}{|c|c|c|c|c|c|c|c|c|c|c|}
\hline \multirow[b]{2}{*}{ Analysis* } & \multicolumn{2}{|c|}{ Sample size, $\mathrm{n}$} & \multirow[b]{2}{*}{ Outcomet } & \multirow[b]{2}{*}{$\Delta \mathrm{C}, €(95 \% \mathrm{Cl}) \neq$} & \multirow[b]{2}{*}{$\Delta \mathrm{E}$, point $(95 \% \mathrm{Cl})$} & \multirow[b]{2}{*}{ ICER, €/point } & \multicolumn{4}{|c|}{ Distribution on CE plane; (\%) } \\
\hline & Pre & DD & & & & & NE & SE & SW & NW \\
\hline \multirow[t]{4}{*}{ Main analysis } & 141 & 148 & $\begin{array}{l}\text { Generic HR-QoL } \\
(0-1) \S\end{array}$ & $-845(-1781$ to -88$)$ & $0.03(-0.01$ to 0.08$)$ & -26022 & 0.07 & 0.87 & 0.06 & 0.00 \\
\hline & 141 & 148 & $\begin{array}{l}\text { Disease-specific HR- } \\
\text { QoL (0-100)ף }\end{array}$ & $-852(-1777$ to -96$)$ & $4.4(-1.1$ to 9.9$)$ & -193 & 0.07 & 0.88 & 0.05 & 0.00 \\
\hline & 144 & 153 & $\begin{array}{l}\text { Treatment satisfaction } \\
(0-10)\end{array}$ & $-821(-1711$ to -75$)$ & $-0.16(-0.53$ to 0.21$)$ & 5213 & 0.06 & 0.19 & 0.74 & 0.01 \\
\hline & 144 & 153 & Pain $(0-10)$ & $-822(-1710$ to -77$)$ & $0.08(-0.37$ to 0.52$)$ & -10517 & 0.07 & 0.61 & 0.32 & 0.00 \\
\hline \multirow[t]{4}{*}{$\begin{array}{l}\text { SA1: healthcare } \\
\text { perspective }\end{array}$} & 141 & 148 & $\begin{array}{l}\text { Generic HR-QoL } \\
(0-1) \S\end{array}$ & $-169(-206$ to -130$)$ & $0.03(-0.01$ to 0.08$)$ & -5190 & 0.06 & 0.88 & 0.05 & 0.00 \\
\hline & 141 & 148 & $\begin{array}{l}\text { Disease-specific HR- } \\
\text { QoL }(0-100) 9\end{array}$ & $-169(-206$ to -130$)$ & $4.4(-1.1$ to 9.9$)$ & -38 & 0.06 & 0.89 & 0.05 & 0.00 \\
\hline & 144 & 153 & $\begin{array}{l}\text { Treatment satisfaction } \\
(0-10)\end{array}$ & $-168(-206$ to -132$)$ & $-0.16(-0.53$ to 0.21$)$ & 1068 & 0.06 & 0.19 & 0.75 & 0.00 \\
\hline & 144 & 153 & Pain $(0-10)$ & $-168(-206$ to -132$)$ & $0.08(-0.37$ to 0.52$)$ & -2153 & 0.05 & 0.62 & 0.33 & 0.00 \\
\hline \multirow{4}{*}{$\begin{array}{l}\text { SA2: absenteeism } \\
\text { costs valued using } \\
\text { age-specific and } \\
\text { gender-specific price } \\
\text { weights }\end{array}$} & 141 & 148 & $\begin{array}{l}\text { Generic HR-QoL } \\
(0-1) \S\end{array}$ & -721 (-1666 to 6) & $0.03(-0.01$ to 0.08$)$ & -22203 & 0.09 & 0.85 & 0.06 & 0.00 \\
\hline & 141 & 148 & $\begin{array}{l}\text { Disease-specific HR- } \\
\text { QoL }(0-100) \emptyset\end{array}$ & $-729(-1587$ to 36$)$ & $4.4(-1.1$ to 9.9$)$ & -162 & 0.09 & 0.86 & 0.05 & 0.00 \\
\hline & 144 & 153 & $\begin{array}{l}\text { Treatment satisfaction } \\
(0-10)\end{array}$ & $-700(-1567$ to 33$)$ & $-0.16(-0.53$ to 0.21$)$ & 4445 & 0.06 & 0.19 & 0.72 & 0.03 \\
\hline & 144 & 153 & Pain $(0-10)$ & -701 (-1566 to 33$)$ & $0.08(-0.37$ to 0.52$)$ & -8969 & 0.09 & 0.59 & 0.32 & 0.00 \\
\hline \multirow{4}{*}{$\begin{array}{l}\text { SA3: propensity } \\
\text { score including } \\
\text { education level }\end{array}$} & 141 & 148 & $\begin{array}{l}\text { Generic HR-QoL } \\
(0-1) \S\end{array}$ & $-758(-1732$ to 53$)$ & $0.03(-0.01$ to 0.07$)$ & -24045 & 0.09 & 0.84 & 0.06 & 0.01 \\
\hline & 141 & 148 & $\begin{array}{l}\text { Disease-specific HR- } \\
\text { QoL (0-100)ף }\end{array}$ & -762 ( -1736 to 46$)$ & $3.44(-2.06$ to 8.93$)$ & -222 & 0.09 & 0.81 & 0.09 & 0.01 \\
\hline & 144 & 153 & $\begin{array}{l}\text { Treatment satisfaction } \\
(0-10)\end{array}$ & -741 (-1661 to 35$)$ & $-0.12(-0.49$ to 0.24$)$ & 6065 & 0.07 & 0.23 & 0.67 & 0.03 \\
\hline & 144 & 153 & Pain (0-10) & $-741(-1664$ to 35$)$ & $0.07(-0.37$ to 0.52$)$ & -9883 & 0.08 & 0.58 & 0.33 & 0.01 \\
\hline
\end{tabular}

*Main analysis: SA2 and SA3 were adjusted for propensity score and work status (yes/no), whereas SA1 was adjusted for propensity score only.

tHigher value indicates better outcome.

$\ddagger$ All costs are expressed in Euros 2019. ${ }^{35} 36$

$\S$ Assessed in participants $\geq 4$ years old using the Euro0ol Five-Dimensional Questionnaire ${ }^{2627}$

ๆAssessed in participants $\geq 4$ years old using four different validated functional outcome questionnaires, ${ }^{30-33}$ all converted to a $0-100$ scale for comparison. ${ }^{34}$

$\triangle C$, difference in costs; $C E$ plane, cost-effectiveness plane; $D D$, direct discharge; $\triangle E$, difference in effects; $H R$-QoL, health-related quality of life; ICER, incremental cost-effectiveness ratio; NE, northeast quadrant of the CE plane, indicating that DD is more effective and more costly than standard care; NW, northwest quadrant of the CE plane, indicating that DD is less effective and more costly than standard care; SA, sensitivity analysis; SE, southeast quadrant of the CE plane, indicating that DD is more effective and less costly than standard care; SW, southwest quadrant of the CE plane, indicating that $\mathrm{DD}$ is less effective and less costly than standard care.

perspective as well as a healthcare perspective, for all four effect measures. That is, DD dominates traditional care for generic HR-QoL, disease-specific HR-QoL, and pain; that is, for these outcomes, on average, DD was less costly and more effective. For satisfaction with treatment, on average, DD was less costly, but also less effective compared with traditional care. It is noteworthy, however, that the mean difference in satisfaction with treatment was 0.16 on a 0 to 10 scale in favor of the pre-DD cohort, ${ }^{25}$ which is far from clinically relevant as the minimally clinical important difference for this outcome is estimated at 0.7 .

Table 4 Mean costs and mean cost differences in euro

\begin{tabular}{|c|c|c|c|c|}
\hline \multirow[b]{2}{*}{ Cost category } & \multicolumn{2}{|l|}{ Costs in $€$, mean (SEM) } & \multicolumn{2}{|c|}{ Cost difference in $€$, mean $(95 \% \mathrm{Cl})^{*}$} \\
\hline & Pre-DD cohort $(n=144)$ & DD cohort $(n=153)$ & Unadjusted & Adjustedt \\
\hline Healthcare, totalł & $522(16)$ & $361(11)$ & $-162(-200$ to -124$)$ & $-168(-205$ to -131$)$ \\
\hline Primary healthcare & $67(10)$ & $53(9)$ & $-14(-39$ to 13$)$ & $-16(-41$ to 11$)$ \\
\hline Secondary healthcare & $456(11)$ & $307(4)$ & $-148(-174$ to -127$)$ & $-152(-179$ to -132$)$ \\
\hline Absenteeism, total & $1648(348)$ & $1306(275)$ & -341 (-1232 to 476$)$ & $-645(-1535$ to 100$)$ \\
\hline Patient absenteeism $\ddagger$ & $1591(350)$ & $1301(275)$ & $-289(-1182$ to 537$)$ & $-598(-1492$ to 148$)$ \\
\hline Parent absenteeism§ & $57(10)$ & $5(3)$ & $-52(-75$ to -34$)$ & $-47(-69$ to -31$)$ \\
\hline Travel & $11(0)$ & $5(0)$ & $-7(-8$ to -6$)$ & $-7(-8$ to -6$)$ \\
\hline Total & $2181(353)$ & $1672(277)$ & $-510(-1411$ to 323$)$ & $-822(-1719$ to -67$)$ \\
\hline
\end{tabular}

All costs are expressed in Euros 2019.35 36

*Cost differences were calculated using regression models using bias-corrected and accelerated bootstrapping, with 5000 replications.

tCost differences adjusted for propensity score, and additionally absenteeism costs were adjusted for work status (yes/no) as well.

łIncluding work absenteeism in the days after sustaining the injury (return-to-work), as well as work leave for the purpose of a hospital follow-up visit.

$\S$ Work leave of a parent to accompany a child to the hospital follow-up visit.

$\mathrm{DD}$, direct discharge. 

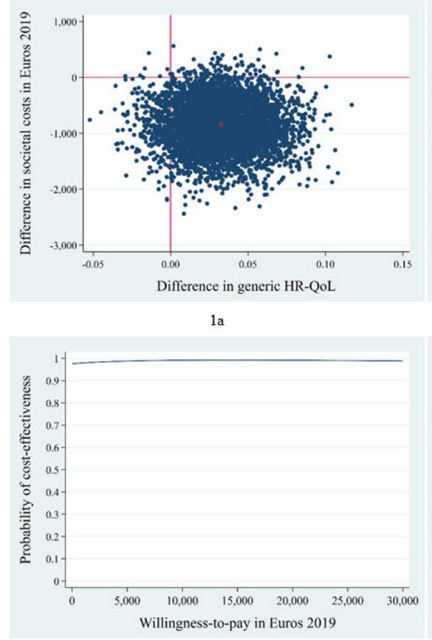

$1 \mathrm{~b}$
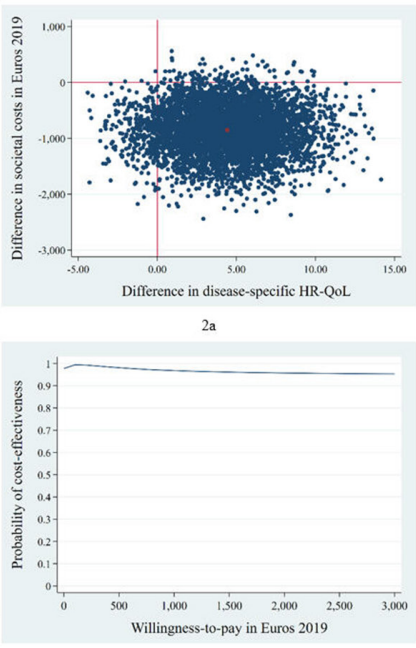
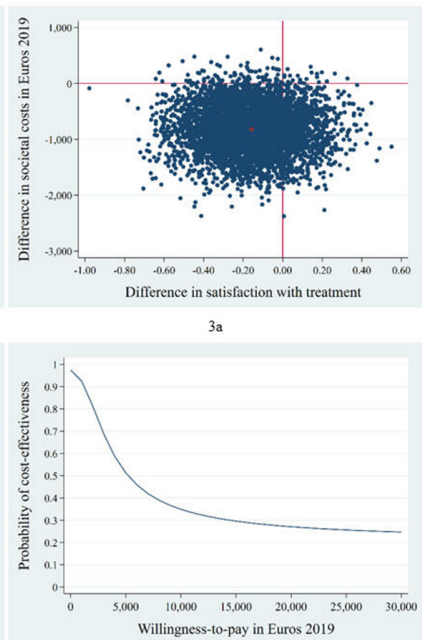
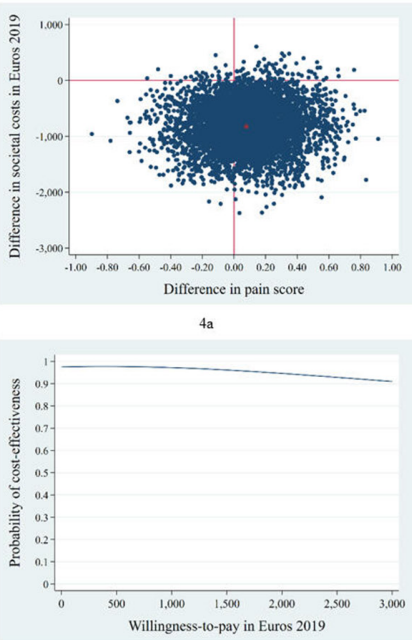

Figure 2 Cost-effectiveness. (a) Cost-effectiveness planes indicating the distribution of incremental cost-effect pairs around its four quadrants and (b) cost-effectiveness acceptability curves indicating the probability of direct discharge being cost-effective in comparison with standard care for different values $(€)$ of willingness-to-pay for (1) generic HR-QoL, (2) disease-specific HR-QoL, (3) pain, and (4) treatment satisfaction. HR-QoL, healthrelated quality of life.

Furthermore, in both cohorts there were relatively high levels of satisfaction; for example, the mean satisfaction with treatment in the DD cohort was 7.95.25

For all outcomes, the CEACs indicate that DD has a high probability of being cost-effective compared with traditional care. For generic HR-QoL, disease-specific HR-QoL, and pain, these probabilities remained the same or only slightly decreased with increasing values of WTP. For satisfaction with treatment, this probability slightly decreased with reasonable increasing values of WTP. This decrease in WTP was caused by the fact that satisfaction with treatment was, on average, lower for DD compared with traditional care, but as mentioned this difference was far from clinically relevant.

Although the aim of this study was to assess cost-effectiveness, our results also suggest that DD is likely to reduce costs across all included cost categories, that is, absenteeism, primary healthcare, secondary healthcare, and travel costs. Based on previous studies, we estimate that approximately 85000 annual ED visits concern SSIs, ${ }^{134}$ and based on the results of the current study, if DD would become the standard of care in the Netherlands, this could potentially result in a national societal cost saving of $€ 70$ million per year. This includes an annual reduction of $€ 14$ million in direct healthcare costs and $€ 54.8$ million lost productivity costs. Although this is a relatively small proportion of the total annual societal costs of injuries (€3.8 billion), ${ }^{1}$ it is also important to consider the additional logistic benefits of DD; that is, in our study on effectiveness of DD, we estimated that national adoption of DD would prevent approximately 142800 outpatient visit clinics per year. ${ }^{25}$

Several previous studies on DD of SSIs have attempted to quantify healthcare cost differences before and after DD, including several non-comparative studies that modeled pre-DD costs based on several assumptions with regard to healthcare utilization, rather than actually measuring pre-DD data. ${ }^{10} 1118$ Furthermore, several previous comparative studies only assessed healthcare costs, most frequently limited to secondary healthcare costs, and did not assess cost-effectiveness. ${ }^{7-9}$ To our knowledge, the current study is the first to assess costs and cost-effectiveness from the broader societal perspective, including both primary healthcare costs and secondary healthcare costs, as well as work absenteeism costs and travel costs. The societal perspective is recommended by the Dutch guidelines for economic evaluations in healthcare. ${ }^{48}$

As a result of this, the comparison of our results with previous studies is limited to comparing healthcare cost differences. It must be noted, however, that the ability to directly compare these differences is further limited by the differences in healthcare (payment) systems across countries as well as the variety of variables used to calculate the cost differences and the costs per item. To illustrate, Seewoonarain et $a l^{9}$ (Great Britain) valued one fracture clinic appointment at $£ 154$, whereas Mackenzie et $a l^{8}$ valued this at $£ 99$ (Scotland), versus $€ 85$ in the current study based on Dutch reference prices (online supplemental appendix B). Moreover, in our study, on average, primary and secondary healthcare costs were reduced by $€ 16$ and $€ 152$ per patient, respectively. Hamilton et $a l^{7}$ reported a mean reduction in healthcare costs of $£ 100$ ( $€ 116$ ) after DD in a comparative study among pediatric patients with a forearm fracture. In this study, however, healthcare costs only included clinic visit, GP visit, and immobilization material costs. Seewoonarain et al compared patients with a torus fracture of the distal radius before and after DD and found a mean reduction of $£ 62$ (€72) in healthcare costs per patient after DD. Their costs only included clinic costs and immobilization costs, which might explain why their total cost reduction was smaller than ours. ${ }^{9}$ Mackenzie et al ${ }^{8}$ estimated the secondary healthcare costs of three types of SSIs before and after DD. Costs included staffing costs, operation costs, and radiology costs. The median reduction per patient was $£ 128$ (€148) for fifth metacarpal fractures, $£ 84$ (€97) for fifth metatarsal fractures, and $£ 138$ (€160) for radial head fractures. ${ }^{8}$

This study has several strengths. Most importantly, this is the first study to evaluate the cost-effectiveness of DD compared with traditional care from a societal perspective. Second, costeffectiveness was analyzed using SUR. This regression technique allows for the correction of the possible correlations between costs and effects. ${ }^{49}$ Third, this study was based on an extensive survey, which allowed a wide range of variables to be included in our total societal cost estimates. Fourth, although randomization might be infeasible for studying redesigns such as DD, our study deals with the non-randomized nature of the study using 
propensity score adjustments. Last, there were no missing data among the participants who responded to the survey.

This study also has several limitations. First, both cohorts were relatively small, and consequently the 95\% CIs surrounding the cost-differences are relatively wide. However, we do not expect our analyses to be extremely underpowered because even our total cost differences were found to be statistically significant, whereas costs are typically underpowered due to their relatively skewed nature. Second, however in keeping with what might be expected, the survey response rate was relatively low, but there were no major differences in baseline characteristics between responding and non-responding participants. ${ }^{25}$ Third, 11 types of SSIs were included and this limits the ability to draw injuryspecific conclusions regarding (cost-)effectiveness of DD versus traditional care. Preliminary post-hoc analyses per injury are provided in online supplemental appendix $\mathrm{C}$ for societal costs, healthcare costs, and the four effect measures that were used in our study. These analyses indicate that DD reduces both societal costs as well as healthcare costs for all injury subgroups, whereas there were no remarkable differences in patient outcomes or patient experiences before and after implementing DD for each injury. However, these injury subgroups are relatively small and therefore lack statistical power; hence, future studies should be conducted to assess this in more detail. Fourth, in this CEA we did not consider the one-time investment that is required to implement DD in a hospital (eg, staffing, resources). However, we have shared our protocols and discharge leaflets with other Dutch hospitals, and these hospitals typically require approximately 3 months to prepare the implementation. Therefore, the associated costs for preparing implementation are relatively low and in our opinion should not refrain hospitals from implementing this model of care. Fifth, outcomes were only measured at a single point in time. Hence, we were unable to include quality-adjusted life years as outcome measure. Sixth, most data were collected prospectively by self-report. Although we do not expect this to differ severely between cohorts, this may have caused socially desirable answers and/or recall bias, for example, for number of GP visits or work absenteeism. Last, patient absenteeism was valued using age-specific and genderspecific price weights, but parent absenteeism was valued using average wage, as the gender and age of the parent accompanying the child during follow-up were unknown.

Future studies should focus on the generalizability of our results in other countries with different healthcare systems, as well as the eligibility of other injuries for DD and associated (cost-)effectiveness. Additionally, studies including larger cohorts should be conducted to strengthen the results, and these cohorts should be large enough to perform subgroup analysis for each injury. Currently multiple hospitals in the Netherlands are implementing DD and therefore this might be achieved by performing multicenter studies in which data are collected in a cooperative and standardized manner. Last, researchers could explore the options to shift the treatment of patients with SSIs from secondary healthcare to primary healthcare (eg, treatment via GP without visiting the ED at all) to further reduce healthcare and societal costs.

In conclusion, the results of this first CEA to compare DD of SSIs with traditional care suggest that DD is likely to be cost-effective compared with "traditional" care with routine follow-up, for generic-specific and disease-specific HR-QoL, satisfaction with treatment, and pain, both from a societal perspective as well as from a healthcare perspective. As a large proportion of musculoskeletal injuries are SSIs, the implementation of DD offers an opportunity to respond to increasing demands, high workloads, and costs. This is necessary to guarantee future high-quality trauma care. Future studies should be performed in larger cohorts to strengthen current findings as well as to test generalizability in other countries.

Collaborators Virtual Fracture Care Study Collaborative: Bas A Uijterwijk (Msc, resident surgery) and Ruth J Stoffels (Msc, data analyst) contributed to the collection of data for this study.

Contributors THG was responsible for the conduct of this study, the methodology, draft of the article, collection of data, and analysis of all data. NJG was responsible for the draft of the article and analysis of all data. JMvD contributed to the methodology, writing of the article, and analysis of all data. RH, RNvV and JCG all contributed to the methodology of this study, implementation of direct discharge, as well as the writing of the article. JCG was the guarantor.

Funding This work was supported by an unrestricted grant provided by Zilveren Kruis Achmea (Leiden, The Netherlands) (grant ID number:WN-2019-060).

Competing interests None declared.

Patient consent for publication Not required.

Ethics approval The study was conducted in accordance with the Declaration of Helsinki and was approved by the local ethical committee of the OLVG Hospital (ref no 18.071) and by its Board of Directors.

Provenance and peer review Not commissioned; externally peer reviewed.

Data availability statement Data are available upon reasonable request. All data are available upon reasonable request to the corresponding author.

Open access This is an open access article distributed in accordance with the Creative Commons Attribution Non Commercial (CC BY-NC 4.0) license, which permits others to distribute, remix, adapt, build upon this work non-commercially, and license their derivative works on different terms, provided the original work is properly cited, appropriate credit is given, any changes made indicated, and the use is non-commercial. See: http://creativecommons.org/licenses/by-nc/4.0/.

ORCID iD

Thiis H Geerdink http://orcid.org/0000-0001-7618-5425

\section{REFERENCES}

1 VeiligheidNL. Cijferrapportage Letsels 2019; Kerncijfers LIS, 2020

2 Beerekamp MSH, de Muinck Keizer RJO, Schep NWL, Ubbink DT, Panneman MJM, Goslings JC. Epidemiology of extremity fractures in the Netherlands. Injury 2017:48:1355-62.

3 Jenkins PJ, Gilmour A, Murray O, et al. The Glasgow fracture pathway: a virtual clinic. BJJ News 2014;2014:22-4.

4 White TO, Mackenzie SP, Carter TH, Jefferies JG, Prescott OR, Duckworth AD, Keating JF. The evolution of fracture clinic design : the activity and safety of the Edinburgh Trauma Triage Clinic, with one-year follow-up. Bone Joint J 2017;99-B:503-7.

5 Ferguson KB, McGlynn J, Jenkins P, Madeley NJ, Kumar CS, Rymaszewski L. Fifth metatarsal fractures - Is routine follow-up necessary? Injury 2015:46:1664-8.

6 Geerdink TH, Haverlag R, van Veen RN, Bouwmeester OVA, Goslings JC. [Direct discharge from the ED for patients with simple stable injuries: a Dutch pilot study]. Ned Tijdschr Geneeskd 2020;164:D4604. [Epub ahead of print: 2502 2020].

7 Hamilton TW, Hutchings L, Alsousou J, Tutton E, Hodson E, Smith CH, Wakefield J, Gray $B$, Symonds $S$, Willett $K$. The treatment of stable paediatric forearm fractures using a cast that may be removed at home. Bone Joint J 2013;95-B:1714-20.

8 Mackenzie SP, Carter TH, Jefferies JG, Wilby JBJ, Hall P, Duckworth AD, Keating JF, White TO. Discharged but not dissatisfied: outcomes and satisfaction of patients discharged from the Edinburgh trauma triage clinic. Bone Joint J 2018;100-B:959-65.

9 Seewoonarain S, Babu S, Sangoi D, Avasthi A, Ricketts D. Introducing a virtual fracture clinic increases efficiency and reduces costs in Torus fracture management. Pediatr Qual Saf 2019:4:e202.

10 Gleeson L, Murray O. Fracture clinic redesign in the ED: breaking the mould. Emergency Nurse New Zealand 2016:14-17.

11 Gleeson L, Murray O. Fracture clinic redesign in the ED: breaking the mould. Part two: Weber a, 5th metacarpal and 5th metatarsal fractures. Emergency Nurse New Zealand 2016:12-15.

12 Matthews AH, Boyd M, Bott AR, Metcalfe JE. Improving emergency department management of paediatric clavicle fractures: a complete audit cycle. Br J Hosp Med 2014:75:287-9.

13 Vardy J, Jenkins PJ, Clark K. Effect of a redesigned fracture management pathway and "virtual" fracture clinic on ED performance (BMJ Open (2014) 4, (e005282)). BM Open 2014:4:e005282.

14 Bhattacharyya R, Jayaram PR, Holliday R, Jenkins P, Anthony I, Rymaszewski L. The virtual fracture clinic: reducing unnecessary review of clavicle fractures. Injury 2017; $48: 720-3$. 
15 Breathnach O, O'Reilly M, Morrissey K, Conlon B, Sheehan E. Electronic referrals for virtual fracture clinic service using the National integrated medical imaging system (NIMIS). Ir J Med Sci 2019;188:371-7.

16 Brogan K, Bellringer S, Akehurst H, Gee C, Ibrahim N, Cassidy L, Rogers B, Gibbs J. Virtual fracture clinic management of fifth metatarsal, including Jones', fractures is safe and cost-effective. Injury 2017;48:966-70.

17 Brooksbank K, Jenkins PJ, Anthony IC, Gilmour A, Nugent MP, Rymaszewski LA. Functional outcome and satisfaction with a "self-care" protocol for the management of mallet finger injuries: a case-series. J Trauma Manag Outcomes 2014;8:21.

18 Callender 0 , Koe S. Using softcast to treat torus fractures in a paediatric emergency department. Ir Med J 2015;108:117.

19 Evans D, Hardman J, Middleton SD, Anakwe RE. Developing a virtual fracture clinic for hand and wrist injuries. J Hand Surg Eur Vol 2018;43:893-4.

20 Gamble D, Jenkins PJ, Edge MJ, Gilmour A, Anthony IC, Nugent M, Rymaszewski LA. Satisfaction and functional outcome with "self-care" for the management of fifth metacarpal fractures. Hand 2015;10:607-12.

21 Jayaram PR, Bhattacharyya R, Jenkins PJ, Anthony I, Rymaszewski LA. A new "virtual" patient pathway for the management of radial head and neck fractures. J Shoulder Elbow Surg 2014;23:297-301.

22 Little M, Huntley D, Morris J, Jozsa F, Hardman J, Anakwe RE. The virtual fracture clinic improves quality of care for patients with hand and wrist injuries: an assessment of 3709 patients. J Hand Surg Eur Vol 2020;45:748-53.

23 O' Reilly M, Breathnach O, Conlon B, Kiernan C, Sheehan E. Trauma assessment clinic: virtually a safe and smarter way of managing trauma care in Ireland. Injury 2019;50:898-902.

24 Robinson PM, Sim F, Latimer M, Mitchell PD. Paediatric fracture clinic re-design: incorporating a virtual fracture clinic. Injury 2017;48:2101-5.

25 Geerdink TH, Augustinus S, Groen JJ, van Dongen JM, Haverlag R, van Veen RN, Goslings JC. Direct discharge from the emergency department of simple stable injuries: a propensity score-adjusted non-inferiority trial. Trauma Surg Acute Care Open 2021;6:e000709.

26 Herdman M, Gudex C, Lloyd A, Janssen M, Kind P, Parkin D, Bonsel G, Badia X. Development and preliminary testing of the new five-level version of EQ-5D (EQ-5D5L). Qual Life Res 2011;20:1727-36.

27 Wille N, Badia X, Bonsel G, Burström K, Cavrini G, Devlin N, Egmar A-C, Greiner W, Gusi N, Herdman M, et al. Development of the EQ-5D-Y: a child-friendly version of the EQ-5D. Qual Life Res 2010;19:875-86.

28 M Versteegh M, M Vermeulen K, M A A Evers S, de Wit GA, Prenger R, A Stolk E. Dutch tariff for the five-level version of EQ-5D. Value Health 2016;19:343-52.

29 Lamers LM, Stalmeier PFM, McDonnell J, Krabbe PFM, van Busschbach JJ. [Measuring the quality of life in economic evaluations: the Dutch EQ-5D tariff]. Ned Tijdschr Geneeskd 2005:149:1574-8.

30 Beaton DE, Wright JG, Katz JN, . Upper Extremity Collaborative Group. Development of the QuickDASH: comparison of three item-reduction approaches. J Bone Joint Surg Am 2005;87:1038-46.

31 Binkley JM, Stratford PW, Lott SA, Riddle DL. The lower extremity functional scale (LEFS): scale development, measurement properties, and clinical application. North American orthopaedic rehabilitation research network. Phys Ther 1999;79:371-83.
32 Irwin DE, Gross HE, Stucky BD, Thissen D, DeWitt EM, Lai JS, Amtmann D, Khastou L, Varni JW, DeWalt DA. Development of six PROMIS pediatrics proxy-report item banks. Health Qual Life Outcomes 2012;10:22.

33 Terwee CB, Roorda LD, de Vet HCW, Dekker J, Westhovens R, van Leeuwen J, Cella D, Correia H, Arnold B, Perez B, et al. Dutch-Flemish translation of 17 item banks from the patient-reported outcomes measurement information system (PROMIS). Qual Life Res 2014;23:1733-41.

34 Wiertsema SH, van Dongen JM, Geleijn E, Huijsmans RJ, Bloemers FW, de Groot V, Ostelo RW. Cost-Effectiveness of the transmural trauma care model (TTCM) for the rehabilitation of trauma patients. Int J Technol Assess Health Care 2019;35:307-16.

35 Hakkaart-Van Roijen L, Van der Linden N, Bouwmans C, et al. Kostenhandleiding: Methodologie van kostenonderzoek en referentieprijzen voor economische evaluaties in de gezondheidszorg. 2015.

36 StatLine. Consumentenprijzen; prijsindex 2015=100. 2020. https://opendata.cbs.nl/ statline/\#/CBS/nl/dataset/83131NED/table?ts=1588863898043.

37 Miyamoto GC, Lin C-WC, Cabral CMN, van Dongen JM, van Tulder MW. CostEffectiveness of exercise therapy in the treatment of non-specific neck pain and low back pain: a systematic review with meta-analysis. Br J Sports Med 2019;53:172-81.

38 van de Graaf VA, van Dongen JM, Willigenburg NW, Noorduyn JCA, Butter IK, de Gast A, Saris DBF, van Tulder MW, Poolman RW, . ESCAPE Research Group. How do the costs of physical therapy and arthroscopic partial meniscectomy compare? A trial-based economic evaluation of two treatments in patients with meniscal tears alongside the escape study. Br J Sports Med 2020;54:538-45.

39 van Dongen JM, Groeneweg R, Rubinstein SM, Bosmans JE, Oostendorp RAB, Ostelo RWJG, van Tulder MW. Cost-Effectiveness of manual therapy versus physiotherapy in patients with sub-acute and chronic neck pain: a randomised controlled trial. Eur Spine J 2016;25:2087-96.

40 Statistiek CBvd. Education level. 2018. https://www.cbs.nl/en-gb/news/2018/20/wellbeing-not-distributed-equally/education-level.

41 IBM Corp. IBM SPSS statistics for windows, version 27.0. Armonk, NY: IBM Corp, 2020.

42 Statacorp. Stata statistical software: release 16. College Station, TX: StataCorp LLC, 2019.

43 Becker SO, Ichino A. Estimation of average treatment effects based on propensity scores. Stata J 2002:2:358-77.

44 Drummond MF, Sculpher MJ, Claxton K, et al. Methods for the economic evaluation of health care programmes: Oxford university press, 2015.

45 Black WC. The CE plane: a graphic representation of cost-effectiveness. Med Decis Making 1990;10:212-4.

46 Fenwick E, O'Brien BJ, Briggs A. Cost-effectiveness acceptability curves--facts, fallacies and frequently asked questions. Health Econ 2004;13:405-15.

47 van Dongen JM, Persoon S, Jongeneel G, Bosmans JE, Kersten MJ, Brug J, Nollet F, Chinapaw MJM, Buffart LM. Long-Term effectiveness and cost-effectiveness of an 18-week supervised exercise program in patients treated with autologous stem cell transplantation: results from the EXIST study. J Cancer Surviv 2019;13:558-69.

48 Zwaap J, Knies S, van der Meijden C, et al. Cost-Effectiveness in practice. Zorginstituut Nederland 2015.

49 Willan AR, Briggs AH, Hoch JS. Regression methods for covariate adjustment and subgroup analysis for non-censored cost-effectiveness data. Health Econ 2004:13:461-75 